\title{
Association of Walking Ability In Relation to Participation In Stroke Survivors: A Cross Sectional Study
}

\section{Suchisree Patro ${ }^{1}$, Jasrah Javed *2.}

Oxford college of physiotherapy, 6/9, Begur Road, AB Road, Hongasandra, Bengaluru, Karnataka 560068, India.

\section{ABSTRACT}

Background:Stroke is a neurological condition caused by an immediate injury to the CNS due to vascular sources like cerebral infarction, intracerebral haemorrhage, or subarachnoid haemorrhage. Stroke leads to changes in cognitive and psychological functioning, body disabilities and profound fatigue. After a stroke, patients are likely to produce an asymmetric gait pattern, decreased gait speed and decreased cadence. This leads to restricted independence and participation in the community and social activities. The aim of the study is to analyse the correlation between walking ability and measures of social participation.

Methodology:Forty subjects were screened for inclusion criteria. They were explained about the procedure and gained informed consent for all the tests of walking ability and questionnaires were given for analysing their participation in social life activities. Walking ability was analysed by using 6-minute walk test, 10-meter walk test, Fall Efficacy Scale (FES), and Functional Ambulation Category (FAC). Social participation was analysed by using 3 questionnaires -POPS, IPAQ, and PARTS/M. Spearman correlation analysis was done to analyse the relationship between walking ability and domains and dimensions of social participation.

Results: The correlation analyses revealed that the walking ability measured by 6-minute walktest, 10-meter walk test, FES and FAC scores correlate with the domains anddimensions of social participation by using the questionnaires-POPS, PARTS/M and IPAQ. Measures of walking ability i.e., 6-minute walk test were correlated with satisfaction $(r=0.312$; $p<0.05)$; FES with satisfaction $(r=-0.396 ; p<0.05)$; FAC with satisfaction $(r=0.436$; $p<0.05)$ dimensions of social participation. Measures of walking ability i.e., 10-meter walk test were correlated with major life area domain $(r=-0.407 ; p<0.5)$; FES and general tasks and demands $(r=-0.334 ; p<0.05) ; F A C$ and general tasks and demand domain $(r=0.327 ; p<0.05)$.

Conclusion: Walking ability was significantly correlated with measures of domains and dimensions of social participation.

KEYWORDS: Stroke, POPS, PARTS/M, CVA, Social Participation, Walking Ability.

Address for correspondence: Dr.Jasrah Javed (PT), MPT (Musculoskeletal disorders and Sports), Oxford college of physiotherapy, 6/9, Begur Road, AB Road, Hongasandra, Bengaluru, Karnataka 560068, India. E-Mail: Jasrah.javed04@gmail.com

Access this Article online

\section{Quick Response code}

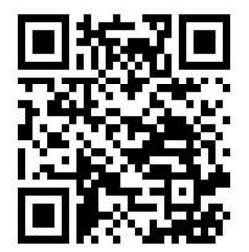

DOI: $10.16965 /$ ijpr.2021.124
Journal Information

International Journal of Physiotherapy and Research

ISSN (E) 2321-1822 | ISSN (P) 2321-8975 https://www.ijmhr.org/ijpr.html

DOI-Prefix: https://dx.doi.org/10.16965/ijpr

\section{Article Information}

Received: 02 Dec 2021

Peer Review: 02 Dec 2021

Revised: None
Accepted: 23 Jan 2022

Published (O): 11 Feb 2022

Published (P): 11 Feb 2022

\section{INTRODUCTION}

Stroke is a neurological condition caused by an immediately focused injury to the central nervous system (CNS) caused by a vascular source such as cerebral infarction, Intracerebral Haemorrhage $(\mathrm{IH})$, or Subarachnoid Haemorrhage (SAH). It is a leading cause of disability and death worldwide [1].

To be classified as a stroke or hemiplegia the focal neurological deficits must be present for at least 24 hours and take longer than 3 weeks to resolve when the duration of signs and symptoms is less than 24 hours the event is 
classified as Transient Ischemic Attack (TIA) and is considered as a warning that stroke will occur in the future if left unattended [2].

Approximately two-thirds of the entire worldwide burden generated by neurological disorders is due to stroke [3].

In India, stroke is one of the most common causes of death and disability. The estimated adjusted prevalence rate of stroke in rural regions is $84-262 / 100,000$, while in urban regions it is 334-424/100,000 [4].

In India, a few surveys were undertaken to determine the Annual Incidence Rates (AIR). In research conducted in Mumbai, AIR was found to be 148 per 100,000 people. For Ischemic stroke, intracerebral haemorrhage and subarachnoid haemorrhage, the age standardised AIRs were 74.8 (95 percent $\mathrm{Cl}$, 66.3-83.2), 10.1 (95 percent $\mathrm{Cl}, 7.0-13.2$ ), and 4.2 (95 percent $\mathrm{Cl}, 2.2-6.1$ ), respectively [5].

Stroke leads to changes in cognitive and psychological functioning, bodily disabilities, profound fatigue. This leads to restricted independence and participation in the community and social activities [6].

Stroke leads to changes in cognitive and psychological functioning, bodily disabilities, profound fatigue. This leads to restricted independence and participation in the community and social activities [7]. Most people with stroke are left with some level of dependency in their everyday tasks, and social involvement is limited as a result of sensorimotor impairment and psychological disorders [8].

Physical disability is one of the major consequences due to stroke and an important health concern for stroke survivors. Among those with physical disabilities, walking is a major problem. Around 51 percent of people lose the ability to walk post-stroke and can persist in a long-term contributor to decreased participation in everyday activities and meaningful life pursuits [9]. Stroke survivors are also reported to have fewer social connections and contacts. Reduced social involvement and interactions, both in quantity and quality, are important variables in selfreported quality of life [10].
Social participation of stroke patients is influenced by many factors like severity of a functional disability, walking capacity quantified as a distance, ability to accept strokerelated problems, adaptation of their behaviour and attitude, and depression. This study showed a correlation of social participation to gait speed [11].

While a person may have a walking capacity, to translate the capacity towards regaining societal functions, the manner in which the social functions are accomplished is also essential. Successful Social participation has many different dimensions [11]. A few or all are required to accomplish different types of social participation effectively.

\section{METHODOLOGY}

Approval was obtained from the Ethical Committee of Oxford college of Physiotherapy, Bengaluru as well as from the places where the study was done.

Forty patients who fulfilled the inclusion and exclusion criteria were taken through convenient sampling for the study. The details and purpose of the study were explained to all the patients for maximum co-operation and a written consent was obtained from them.

Subjects of age 20 years and above male and female willing to participate with the ability to read and write in English language, having the ability to walk with or without assistive device and can follow verbal commands were included. Subjects with musculoskeletal disorders hindering the subject from safe participation and co-morbidities like amputation, severe obstructive pulmonary disease, severe arthritis were excluded as this condition may be difficult for the subject to perform the task. Subjects having behavioural disturbances and psychologically uncooperativeness were also excluded.

\section{Procedure:}

A Cross-sectional study design was used to conduct the current study for a duration of four months. For the fulfillment of the study, each subject underwent tests involved in walking ability and the questionnaires that were involved in social participation. 
All the participants were explained about the purpose and test procedures before their enlistment in the study. Demographic data and details of the subjects were taken before the tests and written consent was obtained.

After selection of subjects, assessment of walking ability was done by 6 - minute walk test, 10-meter walk test, Functional Ambulation Category (FAC), and Fall Efficacy Scale (FES).

Analysis of social participation was done using the Participation Survey of Mobility Limited People (PARTS/M), Impact on Participation and Autonomy (IPAQ), and Participation Objective and Participation Subjective (POPS). The materials used to obtain data were; a stopwatch, inch tape, and 2 chairs.

Spearman correlation was calculated to determine the correlation of the subject's walking ability by 6 -minute walk test, 10 -meter walk test, FAC, FES with domains and dimensions of social participation as measured on PARTS/ $\mathrm{M}, \mathrm{POPS}, \mathrm{IPAQ}$.

Table 2: Domain scores of social participation of the participants $(n=40)$

\section{RESULTS AND DISCUSSION}

The current study was conducted to identify the relationship between walking ability measures and measures of domains and dimensions of social participation in the post-stroke population.

The most important aspect of participation in activities of daily living is walking ability. If walking is affected as in the case of stroke, the participation of the individuals in the society is reduced leading to limitations in their performance.

Significant associations were found between walking ability and the majority of domains and dimensions of social participation.

Table 1: Dimension scores of social participation in the participants $(n=40)$

\begin{tabular}{lc}
\hline \multicolumn{1}{c}{ Dimensions } & (Mean \pm SD) \\
\hline Frequency & $85.26 \pm 15.02$ \\
\hline Level of assistance & $45.19 \pm 18.94$ \\
\hline Limitation & $53.99 \pm 24.73$ \\
\hline Satisfaction & $44.45 \pm 16.65$ \\
\hline Choice and control & $45.19 \pm 18.94$ \\
\hline
\end{tabular}

\begin{tabular}{lc}
\hline \multicolumn{1}{c}{ Domain } & (Mean \pm SD) \\
\hline Learning and applying knowledge & $5.95 \pm 2.06$ \\
\hline General tasks and demands & $112.25 \pm 47.63$ \\
\hline Communication & $19.32 \pm 4.20$ \\
\hline Mobility & $40.65 \pm 14.22$ \\
\hline Self-care & $73.55 \pm 21.71$ \\
\hline Domestic life & $13.45 \pm 7.91$ \\
\hline Interpersonal interactions and social relationships & $18.75 \pm 11.77$ \\
\hline Major life areas & $31.52 \pm 18.49$ \\
\hline Community, social and civic life & $14.1 \pm 10.03$ \\
\hline
\end{tabular}

Table 3: Correlation coefficient $(r)$ of walking ability with domains of social participation $(n=40)$

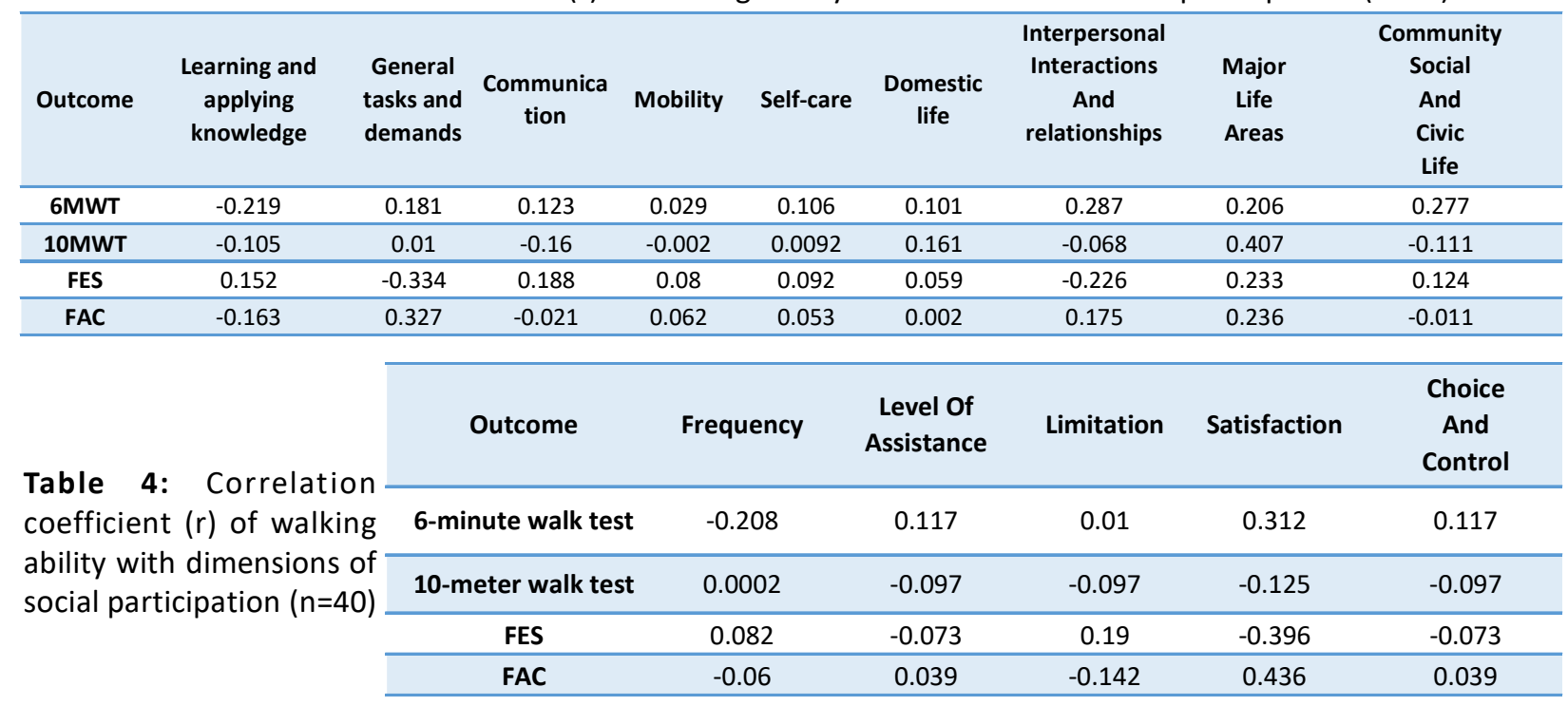



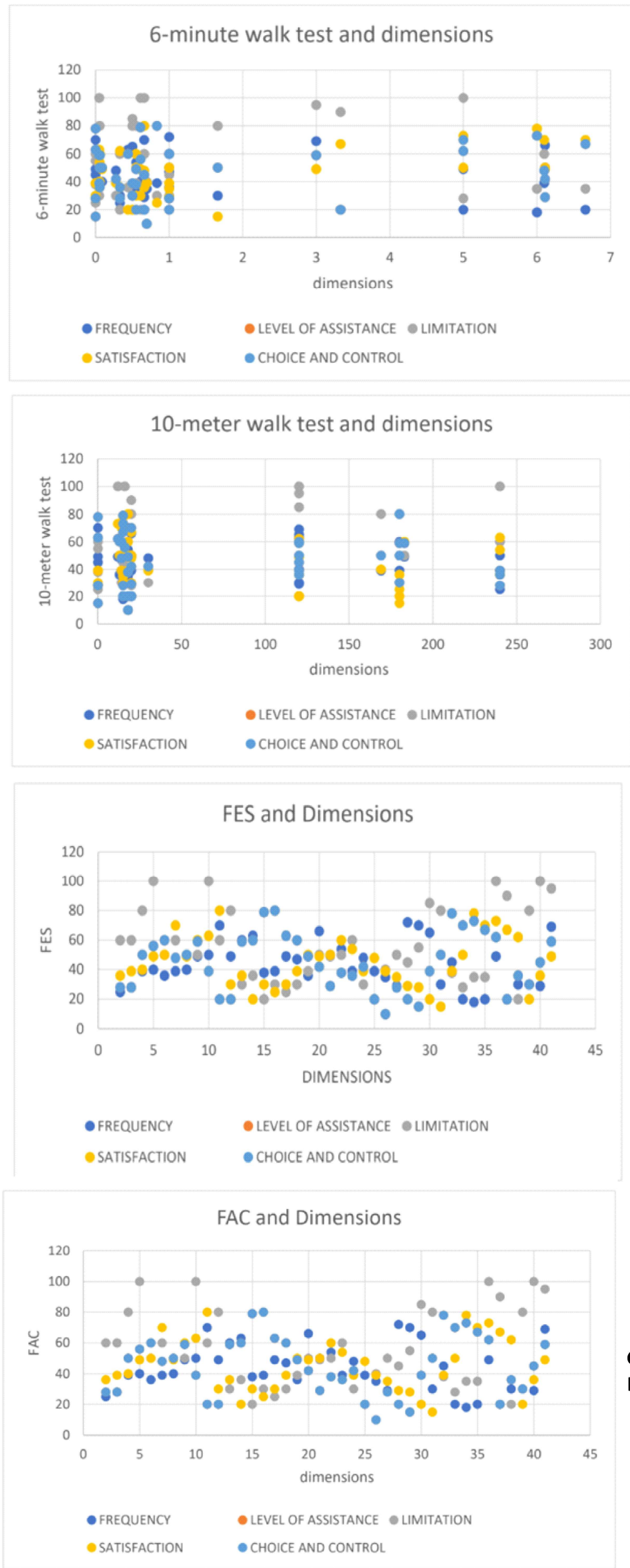

Graph 1: Correlation between 6-minute walk test and dimensions of social participation.

Graph 2: Correlation between 10-meter walk test and dimensions of social participation.

Graph 3: Correlation between FES and Dimensions of social participation.

Graph 4: Correlation between FAC and Dimensions of social participation. 

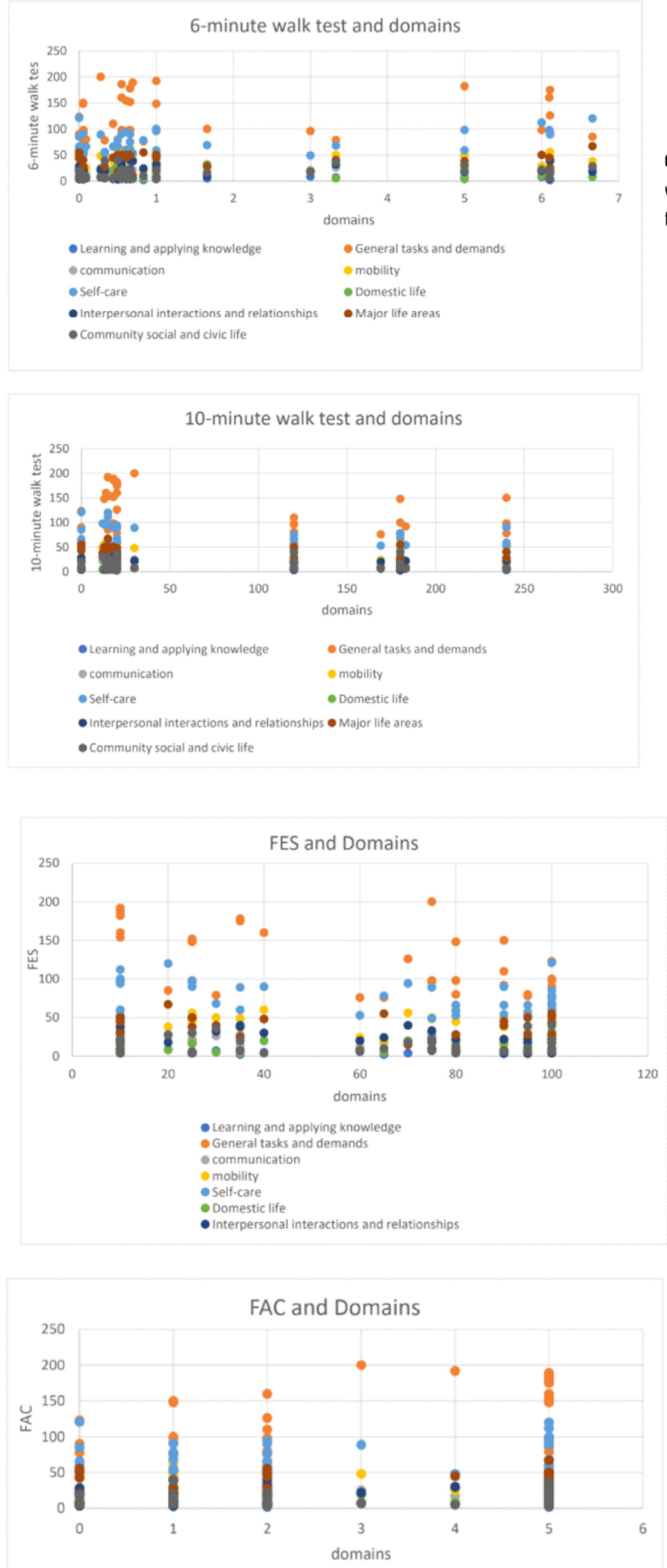

- Learning and applying knowledge
General tasks and demands
- mommility
- Self-care
Domestic life
Interpersonal interactions and relationships
Major life areas
- Community social and civic life
Graph 5: Correlation between 6-minute walk test and domains of social participation.

Graph 6: Correlation between 10-meter walk test and Domains of social participation.

Graph-7: Correlation between FES and Domains of social participation.

Graph 8: Correlation between FAC and Domains of social participation. 
The results suggest that only major life areas and general tasks and demands have a relationship with walking abilities.

The statistical analysis between walking speed assessed by 10 -meter walk test and major life areas domain of social participation revealed a strong relationship. This domain includes activities such as money management, volunteering, and work that needs the subject to navigate streets, public buildings, and commercial places. Hence, the walking speed and the major life area domain of social participation were related. Another exploratory study done by Iza Faria-Fortini et al with the sample size of $n=105$ where walking speed and participation was assessed by 10-meter walk test and LIFE-H questionnaire reported similar results that increase in walking speed was associated with similar domains [11].

The analyses were done between FAC that describes the level of assistance required while ambulation shows a moderate relationship with general tasks and demand domain of social participation. The categories contemplated with this domain are grooming, having meals, using the bathroom and toilet, and doing household activities thatinvolve the use of gait. The higher the level of independence higher is the ability of the participant to carry out the tasks required for daily living.

No relationship was found between the walking ability and certain domains Communication, domestic life, interpersonal interactions and relationships and community, social and civic life. This category takes into account living behaviours that largely entail upper-limb functions, such as writing, as well as language functions, such as interacting with another person.

Communication, interpersonal interactions, and relationships, community, social and civic life require the patient's own interest to interact with the family, society, and community. As the participants are affected with stroke, they tend to have negative attitude and behaviour that leads to negative consequences such as low self-esteem and reduced participation. Therefore, the relationship between them stays unrelated.
Due to lack of social participation, there are chances of worsening of overall bodily functions, strength, flexibility, and mobility leading to consequences like increased risk of fall, muscular atrophy, decreased joint mobility, and hence reduced functional independence.

The learning and applying knowledge domain require the subject to apply the knowledge that the patient has previously learned, which explains why there is no link between walking ability and this domain.

According to the study conducted by Woodman $P$ et al, the synthesis yielded certain ideas concerning social engagement which are following a stroke, participant's independence and autonomy, as well as their social life and relationships, were found to have changed [12].

There was weak relationship between walking ability measures and mobility domain of social participation as the subject exhibited lingering deficits in motor function, muscular strength, coordination, and balance, all of which might affect locomotor ability.

The participant's desire and ability to socialise outside and inside the home were hampered by the stroke's latent effects. Communication challenges, tiredness, vision problems, dizziness, limited focus, memory problems and emotional restrictions were among them [12].

Participants in a few studies perceived loss of ability to drive after a stroke and difficulties using transit as important and strongly associated with a loss of autonomy, independence, and the ability to be spontaneous when going out as significant and strongly associated with a loss of autonomy, independence, and the ability to be spontaneous when going out [13].

The results suggest that only satisfaction dimension that determines the individual's level of satisfaction while performing a task has moderate to strong relationship with walking ability measures.

There is a moderate correlation found between walking endurance assessed by 6- minute walk test and individual satisfaction in the current study. As 6-minute walk test 
gives an estimate of self-evaluation and degree of improvement, this helps the individual in enhanced social participation, confidence building and hence walking independence. Higher the 6-minute walk test scores higher will be the satisfaction, which determined that the participant's degree of satisfaction with the involvement in the tasks would be increased.

Finally, a strong correlation was found between FAC and satisfaction dimension as the subject tends to find greater satisfaction in executing the tasks independently without assistance.

A study done by Ada L et al, supports that improved walking ability increases general well-being by promoting better health and greater community participation [14].

Each person's perception of the barrier's degree differed depending on the activity they were doing. The participants adapted to their new lifestyle after a stroke by accepting their stroke-related issues, improving their condition by balancing their options, and making personal decisions about what they wanted to do after stroke according to their responses in the questionnaires.

The participants had the diverse type of impairments which led to varied limitations in the categories of domains and dimensions of social participation. For instance, the subjects whose balance was impaired found it very difficult in performing tasks that were related to his/her body or had high levels of limitation while engaging in tasks.

The subjects who had upper limb impairment could perform all the activities that included them to ambulate.

Therefore, Lack of physical activity, encouragement and the patient's own interest may be the leading cause for the lack of the relationship between walking ability and few measures of domains and dimensions of social participation.

\section{Limitations:}

Since this was a 1-time measurement of outcome, it is difficult to derive causal relationship from cross-sectional analysis.

\section{CONCLUSION}

This study thereby concludes that there is more than one correlation of walking ability found with the domains and dimensions of the social participation.

\section{ABBREVIATIONS}

FAC- Functional Ambulation Category

ICF -International Classification of Functioning, Disability and Health

IPA- Impact on Participation and Autonomy Questionnaire

PARTS/M- Participation Survey/Mobility

POPS- Participation Objective, Participation Subjective

\section{AUTHORS' CONTRIBUTION}

Dr.Suchsree Patro (PT)- The concept and title of the current study. She has carried out the data collection, designing methodology and protocol and statistical analysis.

https://orcid.org/0000-0003-1560-3413

Dr.Jasrah Javed (PT), - Study design, interpretation of data and drafting of manuscript.

https://orcid.org/0000-0003-3120-4383

\section{ACKNOWLEDGEMENTS}

First and foremost, we want to express our gratitude to God and dedicate the effort to our families for their support. We are extremely grateful to Late Sri S. Narasaraju, Founder Chairman, and SRI S.N.V.L. Narashimaraju, Chairman, Children's Education Society for providing us with all of the necessary resources. Professor Dr. SENTHIL KUMAR of The Oxford College of Physiotherapy, for hissupport, assistance, direction, copious help, and compassionate supervision, deservesspecial mention.Thanks to Principal, Oxford college of physiotherapy, Dr. R. Vasanthan PhD, for providing us with all of the resources and guidance.We want to express our gratitude to Dr.Divya (MPT) and Dr.Rajna (MPT) for theirassistance throughout the research.Very grateful to all the centres for being kind and granting permission to conduct the study. (SUKINO REHABILITATION CENTRE, DC INTERNATIONAL, STEADFAST REHAB)Special thanks to all the volunteers for their time and cooperation; this study wouldnot have been possible without them. 


\section{Conflicts of interest: None}

\section{REFERENCES}

[1]. Sacco R, Kasner S, Broderick J, Caplan L. An Updated Definition of Stroke for the 21st Century: A Statement for Healthcare Professionals from The American Heart Association /American Stroke Association. E. 2013; 44:2064-2089.

[2]. O'Sullivan S, Schmitz T, Fulk G. Physical Rehabilitation, 6th Edition. JP Brothers; 2014.

[3]. Allan R, Martin a, Joshua K, Sashank P. Adam and Victor's Principles of Neurology, 11th Edition. McGraw-Hill Education;2009.

[4]. Pandian JD, Sudhan P. Stroke epidemiology and stroke care services in India. J Stroke. 2013;15(3):128-134. doi:10.5853/jos.2013.15.3.128

[5]. Banerjee TK, Das SK. Fifty years of stroke researches in India. Ann Indian Acad Neurol. 2016;19(1):1-8. doi:10.4103/0972-2327.168631

[6]. MarcheschiE , Koch LV , pessah Rasmussen H, Elf M. Home setting after stroke, facilitators and barriers : A systematic literature review .2017; 26(4 i-iv):433-612: e451-e608.

[7]. Liu TW, Ng SS, Kwong PW, Ng GY. Fear avoidance behaviour, not walking endurance, predicts the community reintegration of community dwelling stroke survivors, 2015 Sep;96(9):1684-90.

[8]. SalbachNM, guilcher S, jaglal SB. Physical therapists' perceptions and use of standardized assessments of walking ability post-stroke. J rehabil med 2011;43:543-49

[9]. Scott C.L., Phillips L.H., Johnston M, Whyte MM, McLeod MJ. Emotion processing and social participation following stroke: study protocol. BMC Neurol2012;12:56.
[10]. Hong E. Comparison of quality of life according to community walking in stroke patients. J Phys Ther Sci. 2015;27(7):2391-2393.

[11]. Iza F, JC P, CDMC F, LF T. 'Associations Between Walking Speed and Participation, According to Walking Status in Individuals with Chronic Stroke'. 1 Jan. 2019 : 341- 48.

[12]. Woodman P, Riazi A, Pereira C, Jones F. Social participation post stroke: a meta- ethnographic review of the experiences and views of community-dwelling stroke survivors. DisabilRehabil. 2014;36(24):2031-43.

[13]. Dickson S, Barbour R, Brady M, Clark AM., Paton G. Patients experience of disruptions associated with post stroke dysarthria. Int J Lang CommunDisord2008;43:135-53.

[14]. Ada L, Dean CM, Lindley R, Lloyd G. Improving community ambulation after stroke: the AMBULATE Trial. BMC Neurol. 2009;9:8.

[15]. Alaszewski A, Alaszewski H, Potter J, Penhale B. Working after a stroke: survivors' experiences and perceptions of barriers to and facilitators of the return to paid employment. DisabilRehabil. 2007;29(24):1858-69.

[16]. Donnan AG, Fisher M, Macleod M, Davis MS ,Stroke.Lancet 2008; 371: 1612-23.

[17]. Mudge S, Stott SN. Outcome measures to assess walking ability following stroke: a systematic review of the literature, Physiotherapy 2007;93(3):189-200.

How to cite this article: Suchisree Patro, Jasrah Javed. Association of Walking Ability In Relation to Participation In Stroke Survivors: A Cross Sectional Study. Int J Physiother Res 2022;10(1):4125-4132. DOI: 10.16965/ ijpr.2021.214 